Article

\title{
An Efficient Chemoselective Reduction of Furan Series Unsaturated Dinitriles
}

\section{Pavel Bobal $^{1, *}$ and Janette Bobalova ${ }^{2}$}

1 Department of Chemical Drugs, Faculty of Pharmacy, University of Veterinary and Pharmaceutical Sciences Brno, Palackeho 1/3, 61242 Brno, Czech Republic

2 Institute of Analytical Chemistry of the Academy of Sciences of the Czech Republic, v. v. i., Veveř́ 97, 60200 Brno, Czech Republic

* Author to whom correspondence should be addressed; E-Mail: bobalp@vfu.cz; Tel.: +420-54156-2927; Fax: +420-54124-0607.

Received: 14 December 2012; in revised form: 28 January 2013 / Accepted: 30 January 2013 / Published: 11 February 2013

\begin{abstract}
An efficient reduction of double bonds conjugated with nitrile groups and acid or base sensitive furan rings with 2-phenylbenzimidazoline generated in situ has been successfully accomplished with high yields and excellent selectivity. The employed reducing agent was prepared in one step from ordinary chemicals. The other advantages of the presented method include mild and convenient reaction conditions, a benign and cost effective reagent, simple work-up and separation of the products. As this process does neither affect cyano and nitro groups nor furan rings, it is a valuable alternative when metal-catalyzed hydrogenations or borohydride reductions have failed.
\end{abstract}

Keywords: chemoselective reduction; regioselective reduction; conjugated olefins; organic hydride compounds; furan ethylenes; unsaturated dinitriles; 2phenylbenzimidazoline

\section{Introduction}

Substituted furans are important and ubiquitous structural units present in large number of natural compounds [1], pharmaceuticals [1,2] and have been widely used as synthetic building blocks for the synthesis of many organic materials [3,4]. Their synthesis, however, still remains a challenge for synthetic chemists. The chemoselective reduction of conjugated double bonds with a furan nucleus 
constitutes a rather troublesome case, as a consequence of the ease of saturation of the heterocyclic moiety $[5,6]$, and the well-known sensitivity of furans to either acids or bases $[7,8]$.

Further, the reduction of substituted propenenitriles to saturated propanenitriles often proceeds with concomitant reduction of the nitrile moiety, polymerization and other side reactions [9]. At present, numerous methods for the reduction of unsaturated nitriles have been developed, including catalytic hydrogenation [10], reductions with organostannic hydrides [11,12], formic acid-triethylamine azeotrope [13], magnesium in methanol [9], sodium borohydride [14,15], sodium cyanoborohydride [16], and many others. Despite the fact that a large group of reducing agents are used for reduction of conjugated unsaturated nitriles, only a limited number might be considered as really selective and accepted as being synthetically useful. To this group belong the so called organic hydride compounds. They can transfer hydrogen to the substrates in the form of hydride anions [17]. These hydride donors are well known in different forms in nature, such as $\mathrm{NADH}, \mathrm{FADH}_{2}$ and others. In recent years, many biomimetic organic hydride compounds were synthesized mainly containing six-membered heterocyclic systems like Hantzsch esters possessing 1,4-dihydropyridine as a redox active centre [18-21]. The other group of heterocyclic compounds having hydrogen-donating ability is a group of five-membered heterocycles, such as dihydrobenzazoles and their usefulness as selective reducing agents has been shown [22-25]. Finally $N, N, N^{\prime}, N^{\prime}, N^{\prime \prime}, N^{\prime \prime}$-hexaethylphosphorous triamide was also successfully used for the reduction of 3-(furan-2-yl)-2-cyanopropenenitrile and its thiophene analog [26].

\section{Results and Discussion}

\subsection{Chemistry}

The selective reduction of conjugated $\mathrm{C}=\mathrm{C}$ bonds with strong electron-withdrawing groups like cyano, nitro or carbonyl groups has been one of the most desirable transformations in organic chemistry. Chemoselective reductions of unsaturated nitriles have attracted much attention for several decades because the reduction products were very important intermediates in organic synthesis.

The goal of the study was to find a suitable method for the chemoselective reduction of 3-phenyl, 3-(thiophen-2-yl) and 3-(5-substituted furan-2-yl)-2-cyanopropenenitriles 1a-g. The products of the reaction e.g. aryl and heteroarylmethylpropanedinitriles, are important intermediates for the synthesis of many biologically active heterocyclic compounds [27].

The substrates for the reduction reaction, 3-phenyl, 3-(thiophen-2-yl) and 3-(5-substituted furan-2yl)-2-cyanopropenenitriles 1a-g, were easily synthesized from the corresponding aldehydes and propanedinitrile, via Knoevenagel condensation catalyzed with piperidine in ethanol [28,29] according to Scheme 1. The 5-substituted furan-2-carbaldehydes starting materials were prepared according to procedures described earlier [30-32].

The reduction of 3-aryl-2-cyanopropenenitriles is well established [9-16,18-25,33-36]. A large numbers of processes have been developed for this purpose, among which the most important are catalytic hydrogenation [33,34] and borohydride reduction [35,36]. We have initially started with an investigation of these methods and their application to substituted furan derivatives. In our hands, reduction of 3-phenyl-2-cyanopropenenitrile (1a) with sodium borohydride in methanol worked well and we isolated 2-benzylpropanedinitrile (3a) [37] in 85\% yield. When applied to 3-(thiophen-2-yl)-2cyanopropenenitrile (1b), the result was rather similar. Borohydride reduction of 3-(furan-2-yl)-2- 
cyanopropenenitrile (1c) also afforded product 3c [38] in a satisfactory $61 \%$ yield. The problem arose when this method of reduction was employed for 5-substituted furan olefins 1d-g. In case of 5-bromoderivative 1d the formation of many side products was observed. Utilization of this process for 5-nitro, 5-phenylsulfanyl and 5-tosylderivatives 1e-g only led to decomposition within a short time and there was no sign of formation of the desired products $\mathbf{3 e}-\mathbf{g}$. Fast decomposition was already observed after addition of the first portion of borohydride. The results are summarized in Table 1. All attempts to suppress decomposition by variations of reaction conditions (temperature, ratio of reagents, solvent, reaction time, etc.) failed. To overcome this problem catalytic hydrogenation on palladium at atmospheric pressure was tested. The reaction time at atmospheric pressure was quite long (10-48 h) and satisfactory results were achieved in case of phenyl and unsubstituted furyl derivatives. The results showed that the reaction of substituted furan-containing olefins did not proceed cleanly, and the formation of side products, impurities and decomposition was noticed. In the case of 5-nitrofuran derivative 1e only decomposition was observed, probably caused by instability of the partially reduced nitrofuran function. Sulphur containing compounds $\mathbf{3 f}, \mathbf{3 g}$ were not tested due to anticipated catalyst poisoning.

Scheme 1. Standard synthesis of 3-phenyl-2-cyanopropenenitrile, 3-(thiophen-2-yl)-2cyanopropenenitrile and 3-(furan-2-yl)-2-cyanopropenenitriles $\mathbf{1 a - g}$.
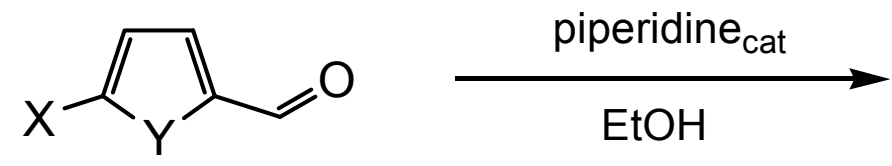

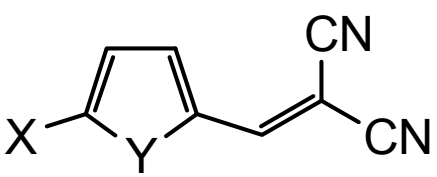

1a-g

$$
\mathrm{Y}=(\mathrm{CH}=\mathrm{CH}), \mathrm{S}, \mathrm{O} \quad \mathrm{X}=\mathrm{H}, \mathrm{Br}, \mathrm{NO}_{2}, \mathrm{C}_{6} \mathrm{H}_{5} \mathrm{~S}, \mathrm{CH}_{3} \mathrm{C}_{6} \mathrm{H}_{4} \mathrm{SO}_{2}
$$

Table 1. Reaction of 3-phenyl, 3-(thiophen-2-yl) and 3-(5-substituted furan-2-yl)-2cyanopropenenitriles 1a-g with 2-phenylbenzimidazoline (2, PBI) generated in situ and with $\mathrm{NaBH}_{4}$.

\begin{tabular}{|c|c|c|c|c|}
\hline Entry & Substrate & Product & Yield $^{a}(\%)$ & Time (h) \\
\hline 1a & $\mathrm{Y}=(\mathrm{CH}=\mathrm{CH}), \mathrm{X}=\mathrm{H}$ & $\mathbf{3 a}$ & $83^{b}(85)^{c}$ & $12^{b}(2)^{c}$ \\
\hline 1b & $\mathrm{Y}=\mathrm{S}, \mathrm{X}=\mathrm{H}$ & $3 \mathbf{b}$ & $78^{b}(69)^{c}$ & $8^{b}(2)^{c}$ \\
\hline 1c & $\mathrm{Y}=\mathrm{O}, \mathrm{X}=\mathrm{H}$ & $3 c$ & $72^{b}(61)^{c}$ & $8^{b}(2)^{c}$ \\
\hline 1d & $\mathrm{Y}=\mathrm{O}, \mathrm{X}=\mathrm{Br}$ & 3d & $80^{b}(-)^{c, d}$ & $8^{b}(1)^{c}$ \\
\hline $1 \mathrm{e}$ & $\mathrm{Y}=\mathrm{O}, \mathrm{X}=\mathrm{NO}_{2}$ & $\mathbf{3 e}$ & $62^{b}(-)^{c, e}$ & $6^{b}(1)^{c}$ \\
\hline 1f & $\mathrm{Y}=\mathrm{O}, \mathrm{X}=\mathrm{C}_{6} \mathrm{H}_{5} \mathrm{~S}$ & 3f & $79^{b}(-)^{c, e}$ & $12^{b}(1)^{c}$ \\
\hline $1 \mathrm{~g}$ & $\mathrm{Y}=\mathrm{O}, \mathrm{X}=\mathrm{CH}_{3} \mathrm{C}_{6} \mathrm{H}_{4} \mathrm{SO}_{2}$ & $3 g$ & $85^{b}(-)^{a, e}$ & $8^{b}(1)^{c}$ \\
\hline
\end{tabular}

From these tests it was evident that we must look for milder and more selective reducing agent. Herein, we decided to explore 2-phenylbenzimidazoline (2 PBI) as an organic hydride compound to test its abilities in reducing electron-deficient olefins with electron-withdrawing substituents (CN 
groups) of the furan series. 2-Phenylbenzimidazoline (2 PBI) is unstable in the air and easily oxidized to aromatic

2-phenylbenzimidazole [24]. Therefore, 2-phenylbenzimidazoline is formed in situ from the ordinary chemicals (i.e., 1,2-diaminobenzene and benzaldehyde) and is expected to be useful as a convenient, mild and selective agent for the reduction of carbon-carbon double bonds in $\alpha, \beta$-unsaturated dinitriles 1a-g. After the reaction of an equimolar amount of 1,2-diaminobenzene and benzaldehyde in ethanol at room temperature in the presence of the same amount of 3-(5-nitrofuran-2-yl)-2-cyanopropenenitrile (1e), 2-[(5-nitrofuran-2-yl)methyl]propanedinitrile (3e) was obtained in $62 \%$ yield. Although a nitro group was inert towards 2-phenylbenzimidazoline, olefinic double bonds conjugated with nitrile groups were reduced efficiently. For optimizing the conditions, several tests with various solvents $\left(\mathrm{MeOH}, \mathrm{THF}, \mathrm{CH}_{3} \mathrm{CN}, \mathrm{DMF}\right)$ were performed. When methanol or tetrahydrofuran were used as a solvent the reaction proceeded smoothly, but the reaction time was longer, probably due to the lower solubility of the starting material 3-(5-nitrofuran-2-yl)-2-cyano-propenenitrile (1e). Acetonitrile and even more dimethylformamide as reaction solvent catalyzed slow formation of side products. Consequently, ethanol remains as an optimal solvent. When attempts were made to improve the yields and remove the traces of starting $\alpha, \beta$-unsaturated dinitrile from the reaction mixtures by increasing the amount of the reagent to 1.2 equivalents, the results showed a disappearance of starting material but the product was a complex mixture. The residues of reducing agent remain in the product. Therefore, all of the experiments were performed with equimolar amounts. In all cases, carbon-carbon double bonds of the 3-(5-substituted furan-2-yl)-2-cyanopropenenitriles were selectively reduced in good yields to give the corresponding 2-[(5-substituted furan-2-yl)methyl]propanedinitriles, while conjugated cyano groups were unaffected, according to Scheme 2.

Scheme 2. Chemoselective reduction of conjugated double bonds with nitrile groups and furan rings accomplished by using 2-phenylbenzimidazoline.

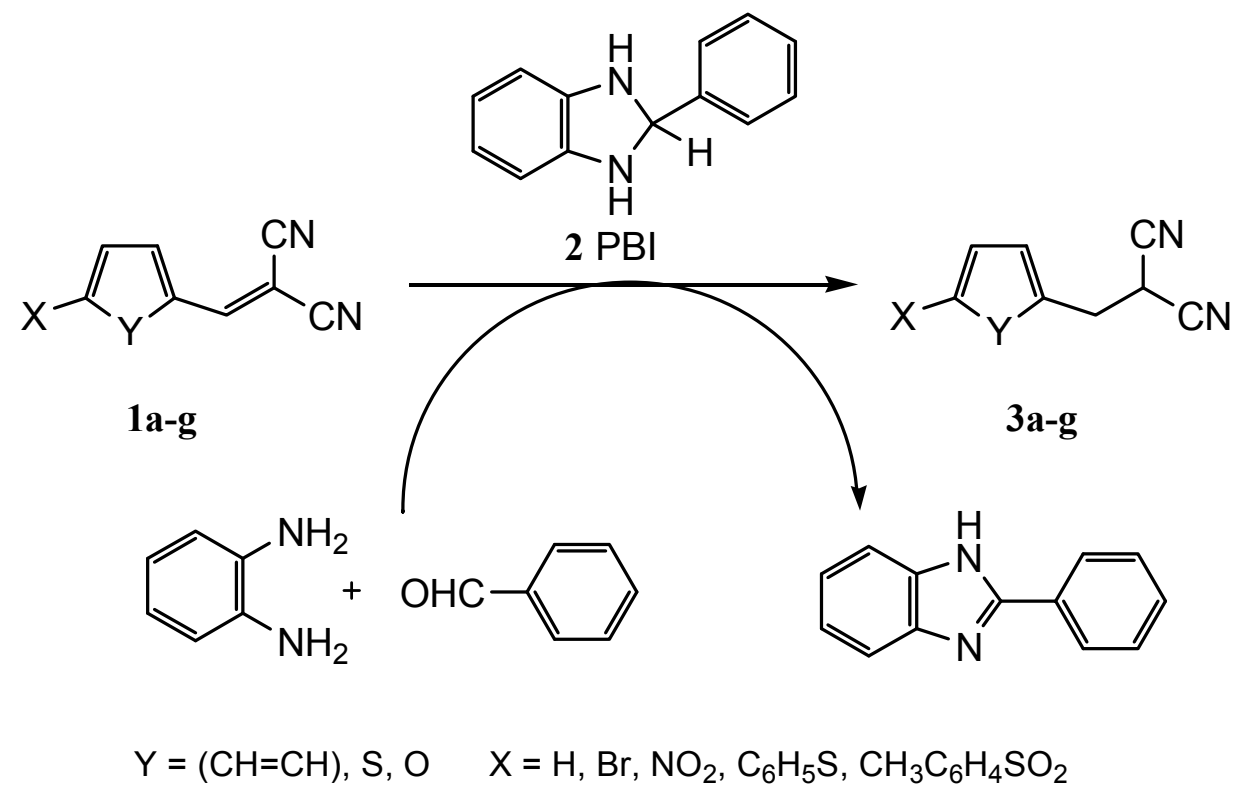

2-Benzylpropanedinitrile (3a), 2-[(thiophen-2-yl)methyl]propanedinitrile (3b) and 2-[(furan-2yl)methyl]propanedinitrile (3c) were also synthesized by reduction with 2-phenylbenzimidazoline 
(2 PBI) formed in situ as well as by $\mathrm{NaBH}_{4}$ reduction. All of the results are summarized in Table 1. In this reaction system, the isolation of 2-benzimidazoline (2 PBI) cannot be achieved, but it is smoothly converted under the reaction conditions to 2-benzimidazole in a practically quantitative yield. After the reaction when ethanol is evaporated, the 2-benzimidazole formed is removed from the reaction mixture by simple filtration of the methylene chloride solution, where this compound is not soluble. The remaining filtrate contains products $\mathbf{3 a}-\mathbf{g}$ in sufficient ( $>95 \%$ ) purity according to HPLC analysis. For analytical purposes the final products were purified by column chromatography and/or recrystallization.

\section{Experimental}

\subsection{General}

All chemicals were reagent grade and were purchased from Sigma-Aldrich (St. Louis, MO, USA) and Acros Organics (Geel, Belgium). TLC analysis was performed on precoated $60 \mathrm{~F}_{254}$ plates (Merck, Darmstadt, Germany). Compounds were visualized by UV light $(254 \mathrm{~nm})$ and evaluated in iodine vapour. HPLC monitoring analyses were performed on an Agilent 1200 series HPLC system equipped with a diode array detection (DAD) system, a quarternary model pump and an automatic injector (Agilent Technologies, Santa Clara, CA, USA). ChemStation Chromatography Software was used for data acquisition. Acetonitrile (HPLC grade, Sigma-Aldrich, 50.0\%) and $\mathrm{H}_{2} \mathrm{O}$ (HPLC grade, Sigma-Aldrich, $50.0 \%$ ) were used as the mobile phase. A Gemini-NX 100 (Phenomenex, Torrance, CA, USA), C18 $3 \mu \mathrm{m}$, $2.0 \times 100 \mathrm{~mm}$ chromatographic column was used with a total flow of $0.2 \mathrm{~mL} / \mathrm{min}$, an injection volume of $5 \mu \mathrm{L}$ and a column temperature of $35^{\circ} \mathrm{C}$. A detection wavelength of $210 \mathrm{~nm}$ was chosen. The melting points were determined on a Boetius PHMK 05 (VEB Kombinat Nagema, Radebeul, Germany) and are uncorrected. All ${ }^{1} \mathrm{H}$ and ${ }^{13} \mathrm{C}$-NMR spectra were recorded in DMSO- $d_{6}$ solutions at ambient temperature on a Bruker Avance III $400 \mathrm{MHz}$ spectrometer (Karlsruhe, Bruker, Germany, $400 \mathrm{MHz}$ for ${ }^{1} \mathrm{H}, 100 \mathrm{MHz}$ for ${ }^{13} \mathrm{C}$ ). Chemical shifts are reported in ppm $(\delta)$. Proton chemical shifts in DMSO- $d_{6}$ are related to the middle of the solvent multiplet $(\delta=2.50) .{ }^{13} \mathrm{C}-\mathrm{NMR}$ spectra were measured using APT pulse sequences. Carbon chemical shifts are referenced to the middle of the solvent multiplet $\left(\delta=39.5\right.$ in DMSO- $d_{6}$ ). Mass spectra were measured using a LTQ Orbitrap Hybrid Mass Spectrometer (Thermo Electron Corporation, Waltham, MA, USA) with direct injection into an APCI source $\left(400{ }^{\circ} \mathrm{C}\right)$ in the positive mode.

\subsection{Synthesis}

\subsubsection{Procedure for the Synthesis of 3-(Phenyl)-2-cyanopropenenitrile (1a) [29]}

To the stirred solution of propanedinitrile $(0.66 \mathrm{~g}, 10 \mathrm{mmol})$ in absolute ethanol $(20 \mathrm{~mL})$ under argon was added benzaldehyde $(1.06 \mathrm{~g}, 10 \mathrm{mmol})$ followed by $2-3$ drops of piperidine. The reaction was refluxed for 2-3 h. The precipitate was formed on cooling the reaction mixture to room temperature. The crude product was filtered and recrystallized from ethanol to yield 3-phenyl-2cyanopropenenitrile (1a) in 75\% yield. 
3.2.2. General Procedure for the Synthesis of 3-(Thiophen-2-yl) and 3-(5-Substituted Furan-2-yl)-2cyanopropenenitriles $\mathbf{1 b}-\mathbf{g}[28,29]$

To the stirred solution of propanedinitrile $(0.66 \mathrm{~g}, 10 \mathrm{mmol})$ in absolute ethanol $(20 \mathrm{~mL})$ under argon was added 2-thenaldehyde or 5-substituted furan-2-carbaldehyde (10 mmol) followed by 2-3 drops of piperidine. The reaction was stirred for $2-3 \mathrm{~h}$ at room temperature. The precipitate was formed during the reaction. The crude product was filtered, washed with cold ethanol and recrystallized from ethanol to yield cyanopropenenitriles $\mathbf{1 b}-\mathbf{g}$ in $56 \%-87 \%$ yields.

3.2.3. Procedure for the Synthesis of 2-Benzylpropanedinitrile with $\mathrm{NaBH}_{4}$

3-Phenyl-2-cyanopropenenitrile (1a, $1.54 \mathrm{~g}, 10 \mathrm{mmol})$ was dissolved in methanol $(50.0 \mathrm{~mL})$ at room temperature. Then $757 \mathrm{mg}(20 \mathrm{mmol})$ of $\mathrm{NaBH}_{4}$ were added in portions. The reaction mixture was stirred at the same temperature for 2 hours, then cooled in ice-bath and $100 \mathrm{ml}$ of water were added. Precipitated crude product was filtrated and recrystallized from ethanol to yield 2benzylpropanedinitrile in $85 \%$ yield.

3.2.4. General Procedure for the Synthesis of Phenyl-, Thiofen-2-yl and 5-Substituted Furan-2-ylmethylpropanedinitriles 3a-g with 2-Phenylbenzimidazoline (2 PBI)

Aryl or heteroaryl 2-cyanopropenenitrile (1a-g, $10 \mathrm{mmol})$ was dissolved in 96\% ethanol (100 $\mathrm{mL})$ under argon. To a stirred mixture was added freshly distilled benzaldehyde (1.06 g, $10 \mathrm{mmol})$ at room temperature, followed by 1,2-diaminobenzene (1.08 g, $10 \mathrm{mmol})$. Reaction mixture was stirred at the same temperature and monitored by TLC. After completion of the reaction, ethanol was removed under reduced pressure and the residue was triturated with methylene chloride $(30 \mathrm{~mL})$. Precipitated 2-phenylbenzimidazole was filtrated off and washed with methylene chloride $(2 \times 10 \mathrm{~mL})$. Methylene chloride was removed from combined filtrates under reduced pressure to yield arylmethyl or heteroarylmethylpropanedinitriles 3a-g. The crude products were sufficiently pure for further synthesis. For analytical purposes the products were purified by column chromatography and/or recrystallization (Table 1).

2-Benzylpropanedinitrile (3a). Yield 83\%; M.p. 90-91 ${ }^{\circ} \mathrm{C}$ (M.p. $88-91{ }^{\circ} \mathrm{C}$ [37]); ${ }^{1} \mathrm{H}-\mathrm{NMR}$ (DMSO- $d_{6}$ ), $\delta: 7.35-7.48(\mathrm{~m}, 5 \mathrm{H}), 4.35(\mathrm{t}, J=7.0 \mathrm{~Hz}, 1 \mathrm{H}), 3.37(\mathrm{~d}, J=7.0 \mathrm{~Hz}, 2 \mathrm{H}) ;{ }^{13} \mathrm{C}-\mathrm{NMR}$ (DMSO- $\left.d_{6}\right), \delta$ : $135.35,129.94,129.32,128.35,114.57(2 \mathrm{C}), 35.01,24.92$.

2-[(Thiophen-2-yl)methyl]propanedinitrile (3b). Yield 78\%; Colourless oil (M.p. 46.5-47 ${ }^{\circ} \mathrm{C}$ [36]); ${ }^{1} \mathrm{H}-\mathrm{NMR}$ (DMSO- $\left.d_{6}\right), \delta: 7.48(\mathrm{~d}, J=5.1 \mathrm{~Hz}, 1 \mathrm{H}), 7.23(\mathrm{~d}, J=3.2 \mathrm{~Hz}, 1 \mathrm{H}), 7.01(\mathrm{dd}, J=5.1,3.2 \mathrm{~Hz}$, $1 \mathrm{H}), 4.25$ (t, $J=6.6 \mathrm{~Hz}, 1 \mathrm{H}), 3.56$ (d, $J=6.6 \mathrm{~Hz}, 2 \mathrm{H}) ;{ }^{13} \mathrm{C}-\mathrm{NMR}$ (DMSO- $d_{6}$ ), $\delta: 134.55,129.82$, $128.15,127.16,111.99(2 \mathrm{C}), 31.53,25.95$.

2-[(Furan-2-yl)methyl]propanedinitrile (3c) [38]. Yield 72\%; Yellowish oil; ${ }^{1} \mathrm{H}-\mathrm{NMR}$ (DMSO- $d_{6}$ ), $\delta$ : $7.56(\mathrm{dd}, J=1.8,0.8 \mathrm{~Hz}, 1 \mathrm{H}), 6.40-6,35(\mathrm{~m}, 2 \mathrm{H}), 4.64$ (t, $J=7.0 \mathrm{~Hz}, 1 \mathrm{H}), 3.42$ (d, $J=7.0 \mathrm{~Hz}, 2 \mathrm{H})$; ${ }^{13} \mathrm{C}-\mathrm{NMR}\left(\mathrm{DMSO}-d_{6}\right), \delta: 147.02,143.67,112.89$ (2C), 110.12, 109.21, 29.80, 23.01. 
2-[(5-Bromofuran-2-yl)methyl]propanedinitrile (3d) [39]. Yield 80\%; Colourless oil; ${ }^{1} \mathrm{H}-\mathrm{NMR}$ $\left(\mathrm{DMSO}-d_{6}\right), \delta: 6.58(\mathrm{~d}, J=3.3 \mathrm{~Hz}, 1 \mathrm{H}), 6.48(\mathrm{dt}, J=3.3,0.73 \mathrm{~Hz}, 1 \mathrm{H}), 5.15(\mathrm{t}, J=6.2 \mathrm{~Hz}, 2 \mathrm{H}), 3.48$ $(\mathrm{d}, J=6.2 \mathrm{~Hz}, 1 \mathrm{H}) ;{ }^{13} \mathrm{C}-\mathrm{NMR}$ (DMSO- $\left.d_{6}\right), \delta: 150.93,121.27,113.57$ (2C), 112.78, 112.23, 27.92, 22.42; HR-MS: for $\mathrm{C}_{8} \mathrm{H}_{6} \mathrm{BrN}_{2} \mathrm{O}[\mathrm{M}+\mathrm{H}]^{+}$calculated 224,9664 m/z, found $224,9683 \mathrm{~m} / \mathrm{z}$.

2-[(5-Nitrofuran-2-yl)methyl]propanedinitrile (3e). Yield 62\%; Brownish oil; ${ }^{1} \mathrm{H}-\mathrm{NMR}$ (DMSO- $d_{6}$ ), $\delta: 7.41(\mathrm{~d}, J=3.3 \mathrm{~Hz}, 1 \mathrm{H}), 6.52(\mathrm{~d}, J=3.3 \mathrm{~Hz}, 1 \mathrm{H}), 4.92$ (t, $J=6.5 \mathrm{~Hz}, 2 \mathrm{H}), 3.55$ (d, $J=6.5 \mathrm{~Hz}, 1 \mathrm{H})$; ${ }^{13} \mathrm{C}-\mathrm{NMR}$ (DMSO- $d_{6}$ ), $\delta$ : 158.62, 150.74, 114.25, 112.87 (2C), 109.39, 27.85, 22.68,; HR-MS: for $\mathrm{C}_{8} \mathrm{H}_{6} \mathrm{~N}_{3} \mathrm{O}_{3}[\mathrm{M}+\mathrm{H}]^{+}$calculated $192.0404 \mathrm{~m} / \mathrm{z}$, found $192.0438 \mathrm{~m} / \mathrm{z}$.

2-\{[(5-(Phenylsulfanyl)furan-2-yl]methyl $\}$ propanedinitrile (3f). Yield 79\%; Yellowish oil; ${ }^{1} \mathrm{H}-\mathrm{NMR}$ (DMSO- $\left.d_{6}\right), \delta: 7.58-7.39(\mathrm{~m}, 5 \mathrm{H}), 6.51(\mathrm{~d}, J=3.3 \mathrm{~Hz}, 1 \mathrm{H}), 6.44(\mathrm{~d}, J=3.3 \mathrm{~Hz}, 1 \mathrm{H}), 5.01(\mathrm{t}, J=6.5 \mathrm{~Hz}$, $2 \mathrm{H}), 3.52(\mathrm{~d}, J=6.5 \mathrm{~Hz}, 1 \mathrm{H}) ;{ }^{13} \mathrm{C}-\mathrm{NMR}$ (DMSO- $\left.d_{6}\right), \delta: 154.27,142.15,135.61,131.16,129.56$, 125.58, 113.86 (2C), 112.91, 112.35, 27.21, 21.91; HR-MS: for $\mathrm{C}_{14} \mathrm{H}_{11} \mathrm{~N}_{2} \mathrm{OS}[\mathrm{M}+\mathrm{H}]^{+}$calculated $255.0587 \mathrm{~m} / \mathrm{z}$, found $255.0559 \mathrm{~m} / \mathrm{z}$.

2-(\{5-[(4-Methylphenyl)sulfonyl]furan-2-yl\}methyl)propanedinitrile (3g). Yield 85\%; M.p. 65-65 ${ }^{\circ} \mathrm{C}$; ${ }^{1} \mathrm{H}-\mathrm{NMR}\left(\mathrm{DMSO}-d_{6}\right), \delta: 7.74(\mathrm{~d}, J=8.0 \mathrm{~Hz}, 2 \mathrm{H}), 7.37(\mathrm{~d}, J=8.0 \mathrm{~Hz}, 2 \mathrm{H}), 6.56(\mathrm{~d}, J=3.4 \mathrm{~Hz}, 1 \mathrm{H})$, $6.12(\mathrm{~d}, J=3.4 \mathrm{~Hz}, 1 \mathrm{H}), 4.89(\mathrm{t}, J=6.6 \mathrm{~Hz}, 2 \mathrm{H}), 3.63(\mathrm{~d}, J=6.6 \mathrm{~Hz}, 1 \mathrm{H}), 2.32(\mathrm{~s}, 3 \mathrm{H}) ;{ }^{13} \mathrm{C}-\mathrm{NMR}$ (DMSO- $d_{6}$ ), $\delta: 155.21,148.38,145.95,138.22,130.14,129.21,112.33$ (2C), 110.82, 107.19, 27.43, 22.19, 21.30; HR-MS: for $\mathrm{C}_{15} \mathrm{H}_{13} \mathrm{~N}_{2} \mathrm{O}_{3} \mathrm{~S}[\mathrm{M}+\mathrm{H}]^{+}$calculated $301.0641 \mathrm{~m} / z$, found $301.0657 \mathrm{~m} / z$.

\section{Conclusions}

In summary, we have demonstrated that the reductions of $\alpha, \beta$-unsaturated dinitriles possessing substituted furan rings could be achieved in high yields and chemoselectivity with 2-phenylbenzimidazoline (2, PBI) formed in situ. The easy work-up and separation of products make this reinvented reagent a promising alternative reducing agent in organic synthesis. The reduction of furan compounds $1 \mathbf{a}-\mathbf{g}$ to $\mathbf{3 a}-\mathbf{g}$ using PBI in ethanol was compatible with various substitution patterns and, in the limited cases examined, with other functional groups (Table 1). A particular advantage of this method over borohydride reduction and catalytic hydrogenation was the regioselective reduction of a conjugated double bond in the presence of groups sensitive to reduction conditions or deactivating the mostly used transition metals like palladium. The principal side reactions were not observed.

\section{Acknowledgements}

This study was supported by the IGA VFU Brno 51/2011/FaF and IGA VFU Brno 63/2011/FaF and by institutional support RVO:68081715 from the Academy of Sciences of the Czech Republic.

\section{References}

1. Keay, B.A.; Dibble, P.W. Furans and their Benzo Derivatives: Applications. In Comprehensive Heterocyclic Chemistry II; Katritzky, A.R., Rees, C.W., Scriven, E.F.V., Eds.; Elsevier: New York, NY, USA, 1996; Volume 2, pp. 395-436. 
2. Mortensen, D.S.; Rodriguez, A.L.; Carlson, K.E.; Sun, J.; Katzenellenbogen, B.S.; Katzenellenbogen, J.A. Synthesis and biological evaluation of a novel series of furans: Ligands selective for estrogen receptor $\alpha . J$. Med. Chem. 2001, 44, 3838-3848.

3. Lipshutz, B.H. Five-membered heteroaromatic rings as intermediates in organic synthesis. Chem. Rev. 1986, 86, 795-819.

4. Hou, X.L.; Cheung, H.Y.; Hon, T.Y.; Kwan, P.L.; Lo, T.H.; Tong, S.Y.; Wong, H.N.C. Regioselective syntheses of substituted furans. Tetrahedron 1998, 54, 1955-2020.

5. Bosshard, P.; Eugster, C.H. The development of the chemistry of furans, 1952-1963. Adv. Heterocycl. Chem. 1967, 7, 377-490.

6. Lee, G.H.; Youn, I.K.; Choi, E.B.; Lee, H.K.; Yon, G.H.; Yang, H.C.; Pak, C.S. Magnesium in methanol $(\mathrm{Mg} / \mathrm{MeOH})$ in organic syntheses. Curr. Org. Chem. 2004, 8, 1263-1287.

7. Dean, F.M. Recent advances in furan chemistry. Part I. Adv. Heterocycl. Chem. 1982, 30, 167-238.

8. Dean, F.M. Recent advances in furan chemistry. Part II. Adv. Heterocycl. Chem. 1982, 31, 237-344.

9. Profitt, J.A.; Watt, D.S.; Corey, E.J. A reagent for the $\alpha, \beta$ reduction of conjugated nitriles. J. Org. Chem. 1975, 40, 127-128.

10. Cope, A.C.; Alexander, E.R. A simultaneous condensation-reduction method for the preparation of ethyl monoalkylcyanoacetates. J. Am. Chem. Soc. 1944, 66, 886-888.

11. Neumann, W.P.; Sommer, R.; Müller, E. Preparation of $N$-stannylketenimines and ketene ethyl stannyl acetals by 1,4-hydrostannation of conjugated systems. Angew. Chem. Int. Ed. 1966, 514-515.

12. Sommer, R.; Müller, E.; Neumann, W.P. Organotin compounds. XXII. Syntheses with $N$-trialkylstannylketenimines. Liebigs Ann. Chem. 1968, 718, 11-23.

13. Nanjo, K.; Suzuki, K.; Sekiya, M. Formic acid reduction. XXVI. $\alpha, \beta$-Reduction of conjugated nitriles with formic acid. Chem. Pharm. Bull. 1977, 25, 2396-2400.

14. Toda, F.; Kanno, M. Reduction of $\alpha, \beta$-unsaturated nitrile to saturated nitrile with sodium borohydride. Bull. Chem. Soc. Jpn. 1976, 49, 2643-2644.

15. Fuentes, L.; Lorente, A.; Soto, J.L. Synthesis of heterocyclic compounds. XIII. 2-Amino-3benzyl-3,5-dicyano-6-methoxy-4-phenyl-3,4-dihydropyridines. J. Heterocycl. Chem. 1979, 16, $273-276$.

16. Hutchins, R.O.; Rotstein, D.; Natale, N.; Fanelli, J.; Dimmel, D. Selective reduction of $\alpha, \beta$-unsaturated esters, nitriles, and nitro compounds with sodium cyanoborohydride. J. Org. Chem. 1976, 41, 3328-3329.

17. Deno, N.C.; Peterson, J.; Saines, G.S. The hydride-transfer reaction. Chem. Rev. 1960, 60, 7-14.

18. Wallenfels, K.; Ertel, W.; Friedrich, K. Mechanism of hydrogen transfer with pyridine nucleotides. XXXI. Reduction of cyano-activated olefins by direct hydrogen transfer from dihydropyridines. Liebigs Ann. Chem. 1973, 1663-1674.

19. Nakamura, K.; Ohno, A.; Oka, S. Reduction by a model of NAD(P)H. 44. Transition metal catalyzed reduction of allylic acetate. Tetrahedron Lett. 1983, 24, 3335-3336.

20. Garden, S.J.; Guimaraes, C.R.W.; Correa, M.B.; Fernandes, D.O.C.A.; Pinto, A.D.C.; Bicca, D.A.R. Synthetic and theoretical studies on the reduction of electron withdrawing group conjugated olefins using the hantzsch 1,4-dihydropyridine ester. J. Org. Chem. 2003, 68, 8815-8822. 
21. Quynh, P.B.N.; Kim, J.N.; Kim, T.H. S-Benzyl isothiouronium chloride as a recoverable organocatalyst for the reduction of conjugated nitroalkenes with Hantzsch ester. Tetrahedron 2012, 68, 6513-6516.

22. Itoh, K.; Ishida, H.; Chikashita, H. The reactions of benzylidenemalononitriles and $\beta$-nitrostyrenes with o-phenylenediamine including the new organic redox reactions between the olefins and 2-phenylbenzimidazolines. Chem. Lett. 1982, 1117-1118.

23. Chikashita, H.; Nishida, S.; Miyazaki, M.; Itoh, K. 2-Phenylbenzimidazoline as a reducing agent in the preparation of malononitriles from $\alpha, \beta$-unsaturated dinitriles. Synth. Commun. 1983, 13, 1033-1039.

24. Chikashita, H.; Nishida, S.; Miyazaki, M.; Morita, Y.; Itoh, K. In situ generation and synthetic application of 2-phenylbenzimidazoline to the selective reduction of carbon-carbon double bonds of electron-deficient olefins. Bull. Chem. Soc. Jpn. 1987, 60, 737-746.

25. Feng, Y.S.; Yang, C.Y.; Huang, Q.; Xu, H.J. Study on comparison of reducing ability of three organic hydride compounds. Tetrahedron 2012, 68, 5053-5059.

26. Hennawy, I.T. Studies of the Reaction of Triaminophosphines with $\alpha, \beta$-unsaturated nitriles. Collect. Czech. Chem. Commun. 1994, 59, 2109-2115.

27. Rewcastle, G.W. Pyrimidines and their Benzo Derivatives. In Comprehensive Heterocyclic Chemistry III; Katritzky, A.R., Ramsden, C.A., Scriven, E.F.V., Taylor, R.J.K., Eds.; Elsevier: New York, NY, USA, 2008; Volume 8, pp. 117-272.

28. Kada, R.; Ilavsky, D.; Goljer, I.; Gaher, P. 3-(5-X-2-Furyl)-2-cyanoacrylonitriles on reaction with 2-cyanomethylbenzothiazole. Collect. Czech. Chem. Commun. 1991, 56, 418-424.

29. Mantri, M.; de Graaf, O.; van Veldhoven, J.; Goeblyoes, A.; von Frijtag Drabbe Kuenzel, J.K.; Mulder-Krieger, T.; Link, R.; de Vries, H.; Beukers, M.W.; Brussee, J.; et al. 2-Amino-6-furan-2yl-4-substituted nicotinonitriles as $\mathrm{A}_{2 \mathrm{~A}}$ adenosine receptor antagonists. J. Med. Chem. 2008, 51, 4449-4455.

30. Antonioletti, R.; D’Auria, M.; De, M.A.; Piancatelli, G.; Scettri, A. Photochemical synthesis of 3and 5-aryl-2-furyl derivatives. J. Chem. Soc. Perkin Trans. 1 1985, 1285-1288.

31. Gilman, H.; Wright, G.F. Nitrofurfural and nitrofurylacrylic acid. J. Am. Chem. Soc. 1930, 52, 2550-2554.

32. Kada, R.; Kovac, J. Furan derivatives. LXV. Preparation and ultraviolet spectra of 5-arylthio- and 5-heteroarylthio-2-furaldehydes. Chem. Zvesti 1975, 29, 402-407.

33. Nakamura, S.; Sugimoto, H.; Ohwada, T. Superacid-catalyzed intramolecular cyclization reaction of arylcyanopropionate: Geminal substitution effect on superelectrophilicity. J. Org. Chem. 2008, 73, 4219-4224.

34. Basu, B.; Das, S.; Das, P.; Nanda, A.K. Co-immobilized formate anion and palladium on a polymer surface: A novel heterogeneous combination for transfer hydrogenation. Tetrahedron Lett. 2005, 46, 8591-8593.

35. Leggans, E.K.; Barker, T.J. Duncan, K.K.; Boger, D.L. Iron(III)/ $\mathrm{NaBH}_{4}$-mediated additions to unactivated alkenes: Synthesis of novel 20'-vinblastine analogues. Org. Lett. 2012, 14, 1428-1431.

36. Tayyari, F.; Wood, D.E.; Fanwick, P.E.; Sammelson, R.E. Monosubstituted malononitriles: Efficient one-pot reductive alkylations of malononitrile with aromatic aldehydes. Synthesis $\mathbf{2 0 0 8}$, 2, 279-285. 
37. Shinkai, S.; Kusano, Y.; Ide, T.; Sone, T.; Manabe, O. Coenzyme Models. XII. Kinetics and mechanisms of 1,4-dihydronicotinamide reduction of carbon-carbon double bonds. Influence of added $\mathrm{Mg}^{2+}$ ion and acetic acid. Bull. Chem. Soc. Jpn. 1978, 51, 3544-3548.

38. Dunham, J.C.; Richardson, A.D.; Sammelson, R.E. Sodium borohydride as the only reagent for the efficient reductive alkylation of malononitrile with ketones and aldehydes. Synthesis 2006, 4 , 680-686.

39. Otaka, T.; Ohira, D. Preparation of [(Thienyl, Furyl, or Pyrrolyl)methyl]malononitrile Derivatives as Pesticides. Jpn. Patent JP2004099597A, 2 April 2004.

Sample Availability: Not available.

(C) 2013 by the authors; licensee MDPI, Basel, Switzerland. This article is an open access article distributed under the terms and conditions of the Creative Commons Attribution license (http://creativecommons.org/licenses/by/3.0/). 